\title{
Research on the Relationship between Evolution of Urban Land Structure and Industrial Structure Transformation: A Case Study of Chengdu City
}

\author{
Qing Kang ${ }^{1}$, Jian-Qiang $\operatorname{Li}^{1} \&$ Jie Ding ${ }^{1}$ \\ ${ }^{1}$ College of Economic and Management, Sichuan Agricultural University, Chengdu, China \\ Correspondence: Qing Kang, College of Economic and Management, Sichuan Agricultural University, Chengdu, \\ China. Tel: 86-139-8171-4823. Email: kangqingchn@163.com
}

Received: May 14, 2012 Accepted: May 31, 2012 Online Published: July 23, 2012

doi:10.5539/esr.v1n2p241 URL: http://dx.doi.org/10.5539/esr.v1n2p241

\begin{abstract}
From lateral perspective, this paper analyzes the relationship between evolution of urban land structure and industrial structure transformation, through proportion change index and Granger method. The empirical study shows three points. First of all, Chengdu land structure change shows that city feature is not perfect, living environment and ecological environment construction needs to be strengthened. Moreover, the industrial structure optimization of Chengdu continues and the tertiary industry gradually occupied a dominant position. Ultimately, in short-term, urban land change drived industry structure transformation, then industry structure transformation feeded back urban land structure change; the synchronization action between urban land structure evolution and industrial structure change has not appeared, and the reciprocal causation of them will come true under the long-time adjusting.
\end{abstract}

Keywords: evolution of urban land structure, industry structure transformation, Chengdu city

\section{Introduction}

The urban land is the basis of social and economic development. The differences in quality and quantity of urban land, and its configuration between different industrial departments will bring different effects to urban development. Theoretical study shows that structure-orientated growth is the essential way of modern economic growth mode. In a certain sense, certain urban industrial structure is mapped through the corresponding urban land use structure, while the contradiction between industrial developments in demand for land growth and the scarcity of land resources has become the core issue of urban land use. Consequently, in the period of high index change, exploring the effect of reasonable evolution of urban land structure on industrial structure optimization is theoretically and realistically significant to macroeconomic control.

The theory about industrial distribution and land location can be traced back to "The Agricultural Location Theory" (Johann Heinrich Von Thunen, 1826), the largest contribution of which is revealing the formation mechanism of land use structure by introducing the location factors into land use study. Besides, anther famous theory was the urban land bid-rent modal of Alonso William, which reflected a basic principle that the growth of urban spatial structure was the result of industrial competition. Industrial economists believed that the most directly reflect of economic development is the change of industrial structure. The optimization of industrial structure was the key reason for the evolution of urban construction land and truly drives force of urban development. On the other hand, the reasonable evolution of urban construction land supplied the material basis for the optimization of industrial structure.

Zhang, Wang Q. and Wang W. (2007) used statistical analysis, exponential analysis and multiple index analysis method to reveal the variation rules between the industrial structure and the land structure from certain angle and to analyze the relationships between them. Lu, Yang and Wen (2010) made a verifying research on the coupling relationship between urban land structure and industrial structure in Chongqing by proportion change index and Granger method. The conclusion showed that, in short term, the coupling relationship did not appear. But in the long time harmony, it would come true. Meng and Zhang (2011) analyzed the relationship among the effectiveness, output value, and amount of land by the output value index for per area, and the odds ratio of value to area. This study area is an example of 18 districts in Beijing during stages of economic development. Authors 
insisted that industrial structure adjustment was the main way to promote the level of intensive land utilization, and that intensive land use policy was also an important means to guide and restrict industrial structure adjustment.

As the evolution of urban land use structure and industrial structure transformation is a complex process, which appears to time-varying non-stationary characteristics. Thus, this paper selects Chengdu City as an example and uses proportion change index and Granger method to analyze and test the relationship between evolution of urban land structure and industrial structure transformation, in order to recommend suggestion for urban economic development.

\section{Study Area, Research Methods and Data Sources}

\subsection{Study Area}

Chengdu is a vice provincial level city, which is located in the central part of Sichuan province. It is an important center city in central and western China. And it is the technology centre, trade center, financial center and transportation hub. The economic aggregate of Chengdu ranked first in the long-term in the 12 western provincial capital cities. In promoting the economic and social development of central and western China, Chengdu plays an important role. As a consequence, there is a referential significance for cities in central and western China and other vice provincial level cities.

\subsection{Research Methods}

\subsubsection{Proportion Change Index}

The structure variation index is an indicator to measure the degree of quantitative structure change. The calculation formula is:

$$
D_{i}=\sum_{i=1}^{n}\left|G_{t}-G_{0}\right|
$$

In which $D_{i}$ is the structure variation index, $G_{t}$ is the proportion of urban land use or industry proportion of period $t, G_{0}$ is the proportion of urban land use or industry proportion of base period, $n$ is the number of type. Based on the formula, this paper calculates the variation degree of urban land use structure and industry structure over the calendar year in Chengdu, then analyzes the both of structure difference by the deviation factor. The deviation factor refers to the absolute value of the difference between the land use structure index and the urban land use structure change index. The larger the deviation factor, the greater gap between the land use structure and industry structure has changed, and vice versa.

\subsubsection{Granger Method}

For two time series $X_{t}$ and $Y_{t}$, if $Y_{t}$ plays role in the forecast; in other words, we use $X_{t}$ forecast $Y_{t}$ better than non-use of $X_{t}$, then $X_{t}$ is the Granger cause for $Y_{t}$. Specifically, we need to establish the p-order lag equation to test whether $X_{t}$ is the Granger cause for $Y_{t}$. The Granger causality model is as follow:

$$
\begin{gathered}
Y_{t}=\lambda+\sum_{i=1}^{p} \partial_{i} X_{t-i}+\sum_{j=1}^{p} \beta_{i} Y_{t-j}+\mu_{i} \\
Y_{t}=\lambda+\sum_{i=1}^{p} \partial_{i} X_{t-i}+\sum_{j=1}^{p} \beta_{i} Y_{t-j}+\mu_{i}
\end{gathered}
$$

In the formulas (2) and (3), $\lambda$ is constant term, $\partial_{i}$ and $\beta_{i}$ present the relevant regression coefficients respectively, $i$ is lag number, $\mathrm{p}$ is maximum lag number, $\mu_{i}$ is error term. The former one aims to test whether $X_{t}$ is the Granger reason of the $Y_{t}$ change, and the latter formula is to test whether the $Y_{t}$ Granger reason causes a $\mathrm{X}_{\mathrm{t}}$ change. The null hypothesis is $H_{0}: \partial_{1}=\partial_{2}=\ldots=\partial_{k}=0, \mathrm{k}=1,2 \ldots \mathrm{p}$. Test the significance of $\partial_{1}, \partial_{2} \ldots \partial_{k}$, if the significance is not 0 , that means the null hypothesis $H_{0}: X_{t}$ is not the Granger reason causing $Y_{t}$ change. Then exchange place of $X_{t}$ and $Y_{t}$, using the same method to test whether the Granger reason causing $\mathrm{X}_{\mathrm{t}}$ change is $H_{0}: Y_{t}$. 


\subsection{Urban Land Classification and Data Sources}

According to "Statistical Yearbook of Chengdu" and "China City Statistical Yearbook" Chengdu will land into residential land, public facilities land, industrial land, warehouse space, external transport sites, roads and squares land, municipal facilities, green space and special land and urban land types 9, 1999-2009, the City and the towns of Chengdu, the land type data were derived from the "China urban Construction Statistical Yearbook" (2000-2010). The social and economic data of this paper comes from "Chengdu Statistical Yearbook" and "China City Statistical Yearbook" (2000-2010).

\section{Chengdu City, the Dynamic Evolution of Urban Land Structure and Industrial Structure Transformation}

\subsection{The Dynamic Evolution of Urban Land Use Structure in Chengdu}

Urban land use structure not only presented as a combination relationship of quantitative proportion and spatial layout, but also reflected on a timely evolution, which has necessarily been mapped by the industrial structure adjustment. The interaction between them is the basis and guarantee for the urban economic growth in space.

As can be seen from the Table 1, residential land accounts for the largest proportion of the whole urban land use structure at $35.96 \%$ in 2009 . Although this proportion was higher by $4.82 \%$ than the upper limit of the domestic standard, compared to $45 \%$ of which in abroad, residential land in Chengdu was obviously insufficient, and the living environment needs to be further improved. Secondly, the proportion of industrial land reached at $20.57 \%$ in 2009, which was higher than that of $15 \%$ at a foreign standard. That is because Chengdu is an industrial city; the proportion of industrial land of Chengdu will be higher. Finally, the proportion of green land increased from $4.33 \%$ in 1999 to $6.57 \%$ in 2009 , while there has some distance from the lowest limit of domestic standard.

From increment view from 1999 to 2009, a proportional decline appears in public facilities land, industrial land, warehousing and storage land, external traffic land and special land, among which the proportion of industrial land and special land decreased to the largest at $2.12 \%$ and $4.73 \%$ respectively. This is mainly due to Chengdu municipal government takes measures to strengthen the intensity of urban land use structure optimization by moving some heavy pollution and labor-intensive industry out from the inner city on the basis of building "world's ecological garden city". Thus, the tertiary industry of location-sensitive and strong capacity to pay are likely to acquire land use right in city center, which attributes to a decline in urban industrial and storage land perception. With speedy development of urban economy, urban agglomeration capacity is stronger, which attractive more people to live and work in the city, hence requiring a higher standard of the urban livability and suitability. Accordingly, the demand for residential land, road and squares land and green land would be increased.

Table 1. Evolution of urban land use structure proportion in Chengdu from 1999-2009

\begin{tabular}{cccccccccc}
\hline Year & $\begin{array}{c}\text { Residential } \\
\text { land } \\
(\%)\end{array}$ & $\begin{array}{c}\text { Public } \\
\text { facilities } \\
\text { land (\%) }\end{array}$ & $\begin{array}{c}\text { Industrial } \\
\text { land } \\
(\%)\end{array}$ & $\begin{array}{c}\text { Warehouse } \\
\text { space } \\
(\%)\end{array}$ & $\begin{array}{c}\text { External } \\
\text { transport } \\
\text { sites (\%) }\end{array}$ & $\begin{array}{c}\text { Roads and } \\
\text { squares } \\
\text { land (\%) }\end{array}$ & $\begin{array}{c}\text { Municipal } \\
\text { facilities land } \\
(\%)\end{array}$ & $\begin{array}{c}\text { Green } \\
\text { space } \\
(\%)\end{array}$ & $\begin{array}{c}\text { Special } \\
\text { land } \\
(\%)\end{array}$ \\
\hline 1999 & 32.36 & 14.17 & 22.69 & 2.65 & 4.22 & 11.56 & 2.64 & 4.33 & 5.39 \\
2000 & 31.83 & 13.97 & 22.25 & 2.58 & 4.13 & 12.20 & 2.59 & 5.19 & 5.25 \\
2001 & 30.59 & 13.37 & 24.53 & 2.48 & 3.94 & 12.57 & 2.5 & 5.16 & 4.86 \\
2002 & 31.12 & 13.18 & 23.9 & 2.45 & 4.51 & 12.38 & 2.6 & 5.64 & 4.21 \\
2003 & 30.54 & 16.24 & 25.15 & 2.33 & 2.12 & 12.19 & 3.35 & 4.37 & 3.62 \\
2004 & 30.17 & 16.22 & 25.14 & 2.34 & 2.39 & 12.27 & 3.33 & 4.55 & 3.59 \\
2005 & 30.53 & 16.5 & 24.81 & 2.24 & 2.23 & 12.3 & 3.06 & 4.88 & 3.46 \\
2006 & 30.25 & 14.3 & 22.89 & 1.87 & 1.36 & 20.09 & 2.79 & 5.68 & 0.76 \\
2007 & 33.73 & 13.69 & 21.14 & 1.85 & 1.3 & 18.81 & 2.95 & 5.74 & 0.8 \\
2008 & 35.93 & 13.27 & 20.35 & 1.5 & 2.38 & 16.88 & 2.02 & 6.96 & 0.72 \\
2009 & 35.96 & 13.44 & 20.57 & 1.57 & 2.81 & 15.72 & 2.71 & 6.57 & 0.66 \\
increment & 3.61 & -0.73 & -2.12 & -1.09 & -1.40 & 4.16 & 0.07 & 2.24 & -4.73 \\
\hline
\end{tabular}

Source: Chengdu Statistical Yearbook (1999-2010) and China City Statistical Yearbook (2000-2010) 


\subsection{The Dynamic Transformation of Industrial Structure in Chengdu}

Industrial structure reveals the proportion constitutes of production factors among various sectors and the interdependence and mutual restriction relationship between them. Industrial structure can be divided into static and dynamic structure. The former one is in certain moment various industry resources allocation, transformation and output. The later one is the composition changing from one form to another form with time goes.

From Figure 1, industrial structure of Chengdu is in the continuous adjustment from 1999 to 2009. The proportion of primary industry decreased from $3.6 \%$ at 1999 to $2.1 \%$ at 2009 , and the decrease amplitude is $41.76 \%$. The whole growth amplitude of secondary industry is $6.34 \%$ that shows a characteristic of rise first then adjustment. The whole rise amplitude of the tertiary industry is $3.71 \%$ which shows the character firstly decreases then increases. Obviously, the overall scale of the tertiary industry has been continuous expansion. But its development speed significantly lags behind the secondary industry. It is thus clear that Chengdu is at the transformation stage from later stage of industrialization to post-industrialization, when the secondary industry and the tertiary industry are increasing and gradually turn to the tertiary industry-led industry pattern.

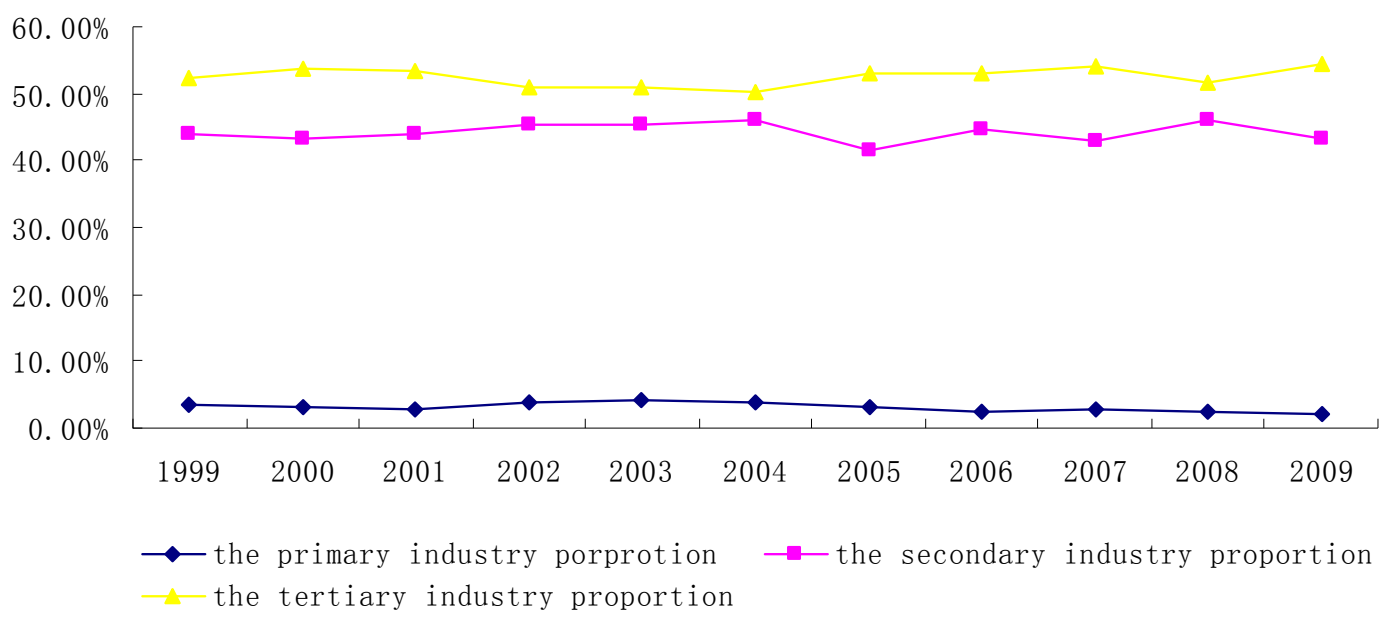

Figure 1. The conversion of industrial structure in Chengdu City from 1999 to 2009

\section{The Relationship between Evolution of Urban Land Use Structure and Industrial Structure Transformation}

\subsection{The Proportion Relationship}

Research on the relationship between urban land structure and industrial structure could be from the quantitative structure and the spatial structure effect in microscopic view. Because of the difficulty of spatial structure data obtained, this paper researches on the effect of evolution of urban use land structure on industrial structure transformation only from the difference of quantitative structure.

According to the formula (1), nearly 11years of Chengdu City, the proportion relationship of urban land use structure and industrial structure were calculated (Table 2). The conclusion shows that the urban land use structure change rate index is steady and presents an increasing trend on the whole, with a fluctuation in the middle. It went up from $3.01 \%$ in 2000 to $23.04 \%$ in 2009 . Compared with the urban land use structure change rate index, the industrial structure change rate index has a larger fluctuation presenting a "W" pattern.

From the deviation coefficient of the urban land use structure change rate index and the industrial structure change rate index, on the whole, from 1999 to 2009, the urban land use structure change rate index is greater than the industrial structure change rate index. The deviation coefficient increases from $0.61 \%$ at 2000 to $8.97 \%$ at 2005 and reached its maximum of $18.80 \%$ at 2008 . The overall tendency shows that the urban land use structure of Chengdu from 1999 to 2009 has large varied amplitude with fast change speed, and the industrial structure change lags behind the urban land use structure change. This is mainly due to the internal function division is not clear, which causes the industrial structure change lag behind. 
Table 2. The change rate index of urban land structure and industrial structure and the deviation coefficient in Chengdu from $1999-2009$

\begin{tabular}{cccc}
\hline Year & $\begin{array}{c}\text { The urban land use structure } \\
\text { change rate index }(\%)\end{array}$ & $\begin{array}{c}\text { The industrial structure } \\
\text { change rate index }(\%)\end{array}$ & $\begin{array}{c}\text { The deviation coefficient } \\
(\%) \\
(1)\end{array}$ \\
\hline 1999 & - & - & - \\
2000 & 3.01 & 2.40 & 0.61 \\
2001 & 7.38 & 1.68 & 5.70 \\
2002 & 7.29 & 3.40 & 3.89 \\
2003 & 11.85 & 3.35 & 8.50 \\
2004 & 12.24 & 4.56 & 7.68 \\
2005 & 12.31 & 3.34 & 8.97 \\
2006 & 20.74 & 2.20 & 18.54 \\
2007 & 20.69 & 3.46 & 17.23 \\
2008 & 23.04 & 4.24 & 18.80 \\
2009 & 20.15 & 4.04 & 16.11 \\
\hline
\end{tabular}

\subsection{Analyses on the Granger Method}

In theory, if any city has all the statistical data of the urban land use structure and industrial structure and could make rational classification, the change tendency of the urban land use structure index will be roughly equal to the industrial structure index. That is the change of urban land use structure could influence the industrial structure change, vice versa.

This paper uses Granger method to analyze the effect of evolution of urban use land structure on industrial structure transformation. It uses the change rate index of urban land use structure (X) and the change rate index of industrial structure (Y) in 1999 as base period to analyze on the Granger method.

\subsubsection{Data Stability Test}

As time series data is not always stable, in order to ensure the reliability of conclusions, the research tries to make stable test selecting the extended ADF by the premise of error term exist serial correlation not determined. The level series of the urban land use structure change rate index and the industrial structure change rate index are expressed as $\mathrm{Y}$ and $\mathrm{X}$. I $\mathrm{Y}$ and I X represents the first-order difference, and II Y and II X are their second-order difference respectively. The result of empirical analysis showed (Table 3) that all samples could not reject the existence of unit root null hypothesis at the $10 \%$ significance level, so the two sequences were not smooth. But the series of the urban land use structure change rate index $(\mathrm{Y})$ and the industrial structure change rate index $(\mathrm{X})$ showed their first-order difference stationary at the $10 \%$ significance level, I (1) process, by the unit root test.

Table 3. ADF test of the temporal variable

\begin{tabular}{ccccccc}
\hline variables & ADF & Test types & $\begin{array}{c}\text { critical } \\
\text { values of } \\
1 \%\end{array}$ & $\begin{array}{c}\text { critical } \\
\text { values of } \\
5 \%\end{array}$ & $\begin{array}{c}\text { critical } \\
\text { values of } \\
10 \%\end{array}$ & $\begin{array}{c}\text { Lag } \\
\text { number }\end{array}$ \\
\hline Y & -2.7353 & Constant and trend & -5.8352 & -4.2465 & -3.5905 & 1 \\
X & -3.2617 & Constant and trend & -5.5201 & -4.1078 & -3.515 & 1 \\
I y & -3.4004 & Constant term & -4.5826 & -3.3209 & -2.8014 & 0 \\
I x & -4.0879 & Constant and trend & -5.8352 & -4.2465 & -3.5905 & 0 \\
II y & -3.8496 & Constant and trend & -6.292 & -4.4504 & -3.7015 & 0 \\
II x & -2.8646 & Constant and trend & -5.1198 & -3.5195 & -2.8984 & 1 \\
\hline
\end{tabular}




\subsubsection{Data Co-integration Test}

On the basis of the result of unit root test, we had practiced whether the error term of regression equation can be smoothly to test and analyze the long-term equilibrium relation between the two series. If the error term is stable, the long-term equilibrium relation between the variable series can be defined, otherwise it does not exist.

Uses E-Views software as an analytical tool to obtain the regression equation of urban land use structure change rate index $(\mathrm{Y})$ and industrial structure change rate index $(\mathrm{X})$ is:

$$
\ln \mathrm{Y}=0.5852+0.2247 \ln \mathrm{X}
$$

$\mathrm{R}^{2}$ of regression model is 0.8056 , while the $\mathrm{F}$ is 20.0705 . Then the unit root test result of the error term showed that at the $10 \%$ significance level of first-order difference, the error term reject the existence of unit root null hypothesis. So that means the long-term equilibrium relation between the series of the urban land use structure change rate index $(\mathrm{Y})$ and the industrial structure change rate index $(\mathrm{X})$ can be defined. As shown in Table 4.

Table 4. ADF text of the error term

\begin{tabular}{ccccccc}
\hline variable & ADF & Test types & $\begin{array}{c}\text { critical values } \\
\text { of } 1 \%\end{array}$ & $\begin{array}{c}\text { critical values } \\
\text { of } 5 \%\end{array}$ & $\begin{array}{c}\text { critical values } \\
\text { of } 10 \%\end{array}$ & $\begin{array}{c}\text { Lag } \\
\text { number }\end{array}$ \\
\hline $\begin{array}{c}\text { The error } \\
\text { term }\end{array}$ & $\begin{array}{c}-3.545 \\
1\end{array}$ & Constant term & -4.5826 & -3.3209 & -2.8014 & 0 \\
\hline
\end{tabular}

\subsubsection{Granger Causality Analysis}

The result of co-integration test represented a the long-term equilibrium relation between the series of the urban land use structure change rate index $(\mathrm{Y})$ and the industrial structure change rate index $(\mathrm{X})$, so we can use Granger causality analysis directly.

As is showed in Table 5, when the lag number is 1 at the $10 \%$ significance level, the probability value of the Granger reason is 0.1653 that evolution of urban land structure does not cause industrial structure transformation. So when confidence level is $83.47 \%$, it refuses the null hypothesis that evolution of urban land use structure does not cause industrial structure change. That means evolution of urban land use structure promotes industrial structure transformation. In contrast, the influence of industrial structure transformation on urban land use structure change was significantly weaker than the later on the former.

The explanation is in the process of implementing Western Development Strategy and constructing the World's Ecological Garden City by Chengdu government, the urban population and the income of urban residents continue to go up, hence demanding for an increasing amount of residential land, road and square land, Municipal utilities land and green land. In the process of optimization, evolution of urban land use structure is faster than industrial structure transformation.

When the lag number is 2 and at the $10 \%$ significance level, the probability value of the Granger reason is 0.3571 that industrial structure change does not cause evolution of urban land use structure. So when confidence level reaches $64.29 \%$, it refused the null hypothesis that industrial structure change does not cause evolution of urban land use structure, which means industrial structure transformation reacts against evolution of urban land use structure, and evolution of urban land use structure does not lead to an industrial structure change.

This is because the Chengdu municipal government moves some heavy pollution and labor-intensive industry out from the city center, providing spaces for information industry and financial industry which need a good location condition and to pay a high government rent to develop. In this way, the proportion of industrial land and Warehousing and storage land were gradually reduced, and urban land use structure will be adjusted.

To sum up, in the short time, there is not the benign interactive relationship between the urban land use structure and the industrial structure, and the change of industrial structure lags behind the dynamic change of urban land use structure. 
Table 5. The Granger test result of urban land use structure change rate index and industrial structure change rate index

\begin{tabular}{ccccc}
\hline Lag length & Granger causality & Freedom & F statistic & Adjoint probability \\
\hline \multirow{2}{*}{1} & X does not Granger Cause Y & 9 & 2.4955 & 0.1653 \\
& Y does not Granger Cause X & 9 & 0.0214 & 0.8886 \\
2 & X does not Granger Cause Y & 8 & 0.4242 & 0.8674 \\
& Y does not Granger Cause X & 8 & 1.4803 & 0.3571 \\
\hline
\end{tabular}

\section{Conclusions and the Policy Suggestion}

\subsection{Conclusions}

The article makes the empirical analysis on the time data of the change rate index of urban land use structure and the change rate index of industrial structure by using Granger method and explains the relationship between evolution of urban land use structure and industrial structure transformation. The result showed that:

1) The industrial structure optimization of Chengdu continues from 1999 to 2009 . According to the theory of Chenery.H and Simon, it is thus clear that Chengdu is at the transformation stage from later stage of industrialization to post-industrialization, when the secondary industry and the tertiary industry are increasing and gradually turn to the tertiary industry-led industry pattern.

2) Chengdu urban land use structure has assumed a situation of a higher proportion of industrial land while a shortage of residential land and green space, which implies a city function to be perfect as well as much to do to strengthen the urban residential and ecological environment construction.

3) The large amplitude and fast speed appears in the industrial structure change, while the reason why the urban land structure lags behind of that is since the ambiguous of urban function partitioning in Chengdu.

4) In short-term, urban land use change promotes the industry structure transformation, then industry structure transformation feeds back the former. Since the influence of the length and lagtime of time series selected, it hasn't generated a reciprocal causation between them, which is an accordance view of the fact. As the interaction between them, the adjustment of urban land use structure hasn't reflected in the industrial structure optimization. Similarly, the two are unlikely to change in the meantime by the influence of land macro-control policies and land price. As a result, the reciprocal causation of them only comes out in a long lasting adjusting.

\subsection{The Policy Suggestion}

The results of study on the relationship between evolution of urban land use structure and industrial structure have important reference meaning to achieve sustainable development of western region economic. It is concluded that:

1) The industrial structure adjustment of Chengdu lags behind the urban construction land use structure change. There is no a reciprocal causation relationship between them, not a reciprocal causation relationship has generated between them. Therefore, Chengdu should guide the industrial location selection by imposing distinguished land taxes based on land price, as well as basing on the rule of industrial structuring evolution and the capital objective condition. All of which spurs to the heavily polluted and labor-intensive industries get far away from the central and residential regions, thus driving the tertiary industry development in the central city.

2) When formulating the land use planning, we must identify the urban function partitioning to promote a scale effect of the similar industries concentration by reducing the production cost. Moreover, we must think much of the effectiveness and feasibility of the planning. The planning should be appropriate advanced and left the flexible scope to adapt to market change and unforeseen factors impacted on land use.

\section{References}

Alonso William. (1965). Location and Land Use. Cambridge: Harvard University Press.

Chenery, H., \& S. Robinson M. Syrquin. (1995). Industrialization and Growth: A Comparative Study. Shanghai: Renmin publishing company.

Clive W. J. Granger. (1969). Investigating causal relations by econometric models and cross-spectral methods. 
Econometrica, 37, 424-459. http://dx.doi.org/10.2307/1912791

Han, X., Wu, P. L., \& Dond, W. L. (2012). An analysis on interaction mechanism of urbanization and industrial structure evolution in Shandong China. Procedia Environmental Sciences, 13, 1291-1300. http://dx.doi.org/10.1016/j.proenv.2012.01.122

He Chunyag, Shi Peijun, \& Chen Jin. (2001). A study on land use/cover change in Beijing area. Geographical Research, 20(6), 679-687.

Huang Xianjin, Peng Buzhuo, \& Zhang Jianxin. (2002). Relationship between Regional Economic Sector Development and Sustainable Land use. Economic Geography, 22(4), 425-429.

Johann Heinrich Von Thunen, \& Wu Hengkang. (1997). The Isolated State. Beijing: the Commercial Press.

Kong Xiangbin, Zhang Fengrong, \& Li Yulan. (2005). Interactive Relationship between Land Use Change and Industrial Change. Resources Science, 27(2), 5-7.

Liu Yanjun, Li Chenggu, \& Sun Di. (2006). Analysis on Process and Power Mechanism of Urbanization Response of Industrial Structure Evolvement in Northeast China. Urban Studies, 13(6), 58-64.

Liu Yansui, \& Chen Baiming. (2002). The study framework of land use /cover change based on sustainable development in China. Geographical Research, 21(3), 324-330.

Lu Chunyang, Yang Qingyuan, \& Wen Feng. (2010). Study on the Relationship between Urban Land Use Structure and Industry Structure---Chongqing as an Example. Urban Studies, 17(1), 102-107.

Wang Siyuan, Zhang Zengxiang, \& Zhou Quangbin. (2002). Study on Spatial-Temporal Features of Land Use/ Land Cover Change Based on Technologies of RS and GIS. Journal of Remote Sensing, 6(3), 223-228.

White, R., \& Engelen, G. (1993). Urban systems dynamic and cellular automata: Fractal structures between order and chaos. Chao, Solitons \& Fractals, 4(4), 563-583. http://dx.doi.org/10.1016/0960-0779(94)90066-3

Xuebing Dong, Shunfeng Song, \& Hui Zhu. (2011). Industrial structure and economic fluctuation--Evidence from China. The Social Science Journal, 48(3), 468-477. http://dx.doi.org/10.1016/j.soscij.2011.05.002

Zhang Ying, Wang Qun, \& Wang Wanmao. (2007). Study on the Relationship between Industrial Structure and Land Structure in China. China Land Science, 21(2), 6-9.

Zhu Huiyi, Li Xiubin, \& He Shujin. (2001). Spatio-temporal Change of Land Use in Bohai Rim. Acta Geogarphica Sinica, 56(3), 253-260. 